Case Study

\title{
Rehabilitation training using a single-joint type hybrid assistive limb for the knee after anterior cruciate ligament reconstruction: an initial case report indicating safety and feasibility
}

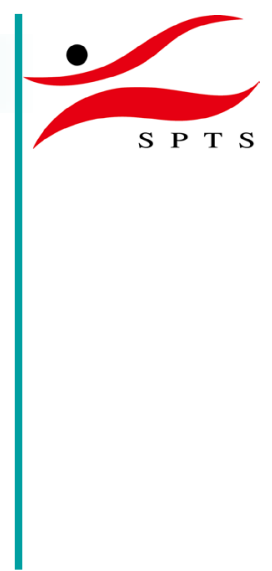

Yuichiro Soma, RPT ${ }^{1)}$, Hirotaka Mutsuzaki, MD, $\mathrm{PhD}^{2,3)^{*}}$, Tomokazu Yoshioka, MD, $\mathrm{PhD}^{4,5)}$, Shigeki Kubota, OT, $\mathrm{PhD}^{4,5)}$, Yukiyo Shimizu, MD, $\mathrm{PhD}^{5}$, , Akihiro Kanamori, MD, $\mathrm{PhD}^{5}$, Masashi YamazaKi, MD, $\mathrm{PhD}^{5}$ )

1) Department of Rehabilitation Medicine, University of Tsukuba Hospital, Japan

2) Department of Orthopaedic Surgery, Ibaraki Prefectural University of Health Sciences Hospital: 4669-2 Ami, Inashiki-gun, Ibaraki 300-0394, Japan

3) Centre for Medical Sciences, Ibaraki Prefectural University of Health Sciences Hospital, Japan

4) Division of Regenerative Medicine for Musculoskeletal System, Faculty of Medicine, University of Tsukuba, Japan

5) Department of Orthopaedic Surgery, Faculty of Medicine, University of Tsukuba, Japan

\begin{abstract}
Purpose] The aim of this report was to describe the safety, feasibility, and efficacy of rehabilitation by knee extension and flexion training using the knee single-joint hybrid assistive limb in a patient after anterior cruciate ligament reconstruction. [Participant and Methods] A 33 year-old male underwent an arthroscopic procedure for anatomic single-bundle anterior cruciate ligament reconstruction with a semitendinosus tendon autograft. Rehabilitation training using the knee single-joint hybrid assistive limb was initiated at postoperative week 18 and repeated weekly for 3 weeks. The patient performed five sets of the knee single-joint hybrid assistive limb-assisted knee-extension-flexion exercises per session at a frequency of 10 exercises/set. [Results] The peak extension torque at all velocities with the limb symmetry index was higher after the hybrid assistive limb intervention (post-intervention) than before using it (pre-intervention). Peak flexion torques at $60 \% \mathrm{~s}$ and $300 \% \mathrm{~s}$ of limb symmetry index were higher post-intervention than pre-intervention. The range of motion in extension and flexion improved from $-2^{\circ}$ (pre-intervention) to $-1^{\circ}$ (post-intervention) and from $124^{\circ}$ to $133^{\circ}$, respectively. The Lysholm score increased from 58 (pre-intervention) to 94 (post-intervention). [Conclusion] The knee single-joint hybrid assistive limb can be used safely for anterior cruciate ligament reconstruction training, without any adverse events. Our results indicate that the knee single-joint hybrid assistive limb training may improve muscle function, effectively overcoming dysfunction. Key words: The single-joint type hybrid assistive limb for the knee joint (knee HAL-SJ), Anterior cruciate ligament reconstruction, Muscle dysfunction
\end{abstract}

(This article was submitted Aug. 12, 2020, and was accepted Oct. 11, 2020)

\section{INTRODUCTION}

Anterior cruciate ligament reconstruction (ACLR) is a common treatment for athletes who aim to return to high-level sporting activity after ACL injury ${ }^{1,2}$. One of the rehabilitation goals after ACLR is to return to pre-injury levels of sports/ activity. However, $35 \%$ of athletes do not return to pre-injury levels within 2 years after ACLR procedure ${ }^{2}$. According to

*Corresponding author. Hirotaka Mutsuzaki (E-mail: mutsuzaki@ipu.ac.jp)

(Supplementary material: refer to PMC https://www.ncbi.nlm.nih.gov/pmc/journals/2193/)

(C2021 The Society of Physical Therapy Science. Published by IPEC Inc.

(c) $(-)$ This is an open-access article distributed under the terms of the Creative Commons Attribution Non-Commercial No DerivaCO ${ }_{\text {BY }}$ ND tives (by-nc-nd) License. (CC-BY-NC-ND 4.0: https://creativecommons.org/licenses/by-nc-nd/4.0/) 
previous studies, quadriceps activation failure after ACLR is not simply an isolated local phenomenon related to atrophy only. This quadriceps activation failure has been attributed to arthrogenic muscle inhibition (AMI), which is caused by neural inhibition $^{3}$. Moreover, harvesting hamstring tendon autografts for ACLR results in weakness of the hamstrings muscle strength at deep knee flexion angles ${ }^{4}$. Therefore, improving long-term muscle weakness and neuromuscular problems after ACLR are important factors to consider during the rehabilitation process.

The single-joint type hybrid assistive limb for the knee (HAL-SJ; HAL-FS01, Cyberdyne, Inc., Japan) is a newly developed wearable robot exoskeleton that provides real-time assistance to limb movements via actuators mounted laterally on the patient's knee joints. The movement of the robot is triggered by bioelectric signals (muscle action potentials) from the muscles. Although previous studies have reported that the knee HAL-SJ is effective in functional recovery following total knee arthroplasty (TKA) and opening wedge high tibial osteotomy ${ }^{5,6)}$, this has not been done after ACLR.

The knee HAL-SJ can facilitate proper movement of knee joint through bioelectric signal feedback from the muscles and providing assisted joint motions with a Cybernic Voluntary Control (CVC) system. We hypothesized that the use of the knee HAL-SJ would result in a new type of neuromuscular training that reduces joint damage and neural inhibition, and also improves muscle dysfunction following ACLR procedures. A neuromuscular training following ACLR is known to be beneficial. In addition, as previously mentioned, there have been reports of improvements in knee joint function using the HAL after TKA in a patient. However, the knee HAL-SJ has been just applied to patients only after TKA or HTO. To date, there are no reports on the efficacy of this device applied to the knee joint in a patient who has undergone ACLR. Therefore, in this case study, we describe the safety, feasibility, and efficacy of rehabilitation training by knee extension and flexion using the knee HAL-SJ in a patient who has undergone ACLR.

\section{PARTICIPANT AND METHODS}

A 33 year-old male (height: $177 \mathrm{~cm}$; weight: $81.1 \mathrm{~kg}$; body mass index: $25.9 \mathrm{~kg} / \mathrm{m}^{2}$; and time to surgery: $3 \mathrm{months}$ ) had injured his ACL while playing basketball. The patient was a recreational athlete who injured his knee during playing sports with noncontact ACL injury mechanisms. The patient then underwent an arthroscopic, anatomic single-bundle ACLR with a semitendinosus tendon autograft and repair of a lateral meniscal lesion (Fig. 1A, B).

A physical therapist treated the patient postoperatively in the hospital. The rehabilitation program was commenced one day postoperatively. A range of motion exercise and weight-bearing exercises were initiated 2 weeks postoperatively. Discharged from the hospital, the patient attended physical therapy once a month, and participated in a rehabilitation program that included muscle strength training and neuromuscular training. Jogging was encouraged after 3 months.

The patient's thigh circumference and lower limb length were measured before fitting the knee HAL-SJ. After measuring the maximum flexion angle and extension angle before the intervention, the knee HAL-SJ assist angle was set so as not to over-assist the knee. Electrodes were attached to the patient's quadriceps and hamstring muscles (the vastus medialis, rectus femoris, vastus lateralis, and biceps femoris, or medial hamstrings) to detect the bioelectric signals from the long axis (along the belly) of each muscle (Fig. 2A, B). The patient was then instructed to perform knee extension and flexion thereby contracting his quadriceps and hamstring muscles ${ }^{5)}$.

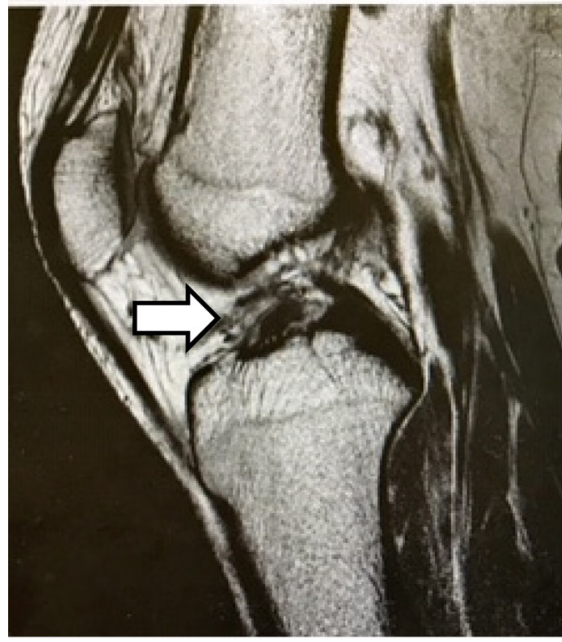

A

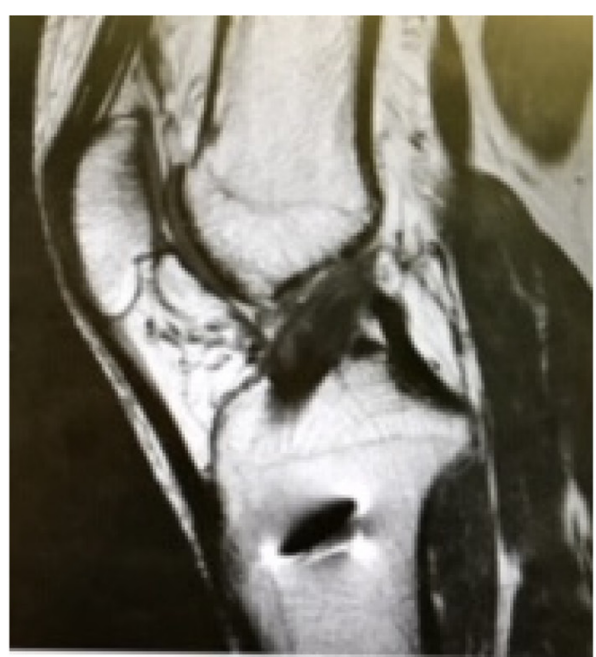

B

Fig. 1. Pre- and postoperative images of the knee joint (sagittal view) of the patient undergoing anterior cruciate ligament reconstruction. A: The lesion (arrow) as visualized by preoperative magnetic resonance imaging.

B: Postoperative image. 
Generally, several anatomical problems occur following ACLR: slightly lax graft tension, partial graft tear, poor synovial coverage, and cyclops-like lesion ${ }^{7)}$. Therefore, while initiating and during rehabilitation training using the knee HAL-SJ, safety should always be taken into consideration. Regarding anterior knee laxity, a previous study showed that the average anterior tibial translation of the involved knee, compared to the uninvolved side, is $1.5 \mathrm{~mm}$ measured using KT-2000 4 months after ACLR ${ }^{8)}$; these values indicate good results for anterior knee laxity. Another study showed that the semitendinosus tendon autografts transform into a histologic structure at least 12 weeks after surgery ${ }^{9}$. Therefore, rehabilitative training using the knee HAL-SJ was commenced 18 weeks postoperatively; it was performed once a week, for a total of 3 sessions (Fig. 3). The CVC mode of the knee HAL-SJ, which was used in this study, could support a patient's voluntary motion based on the voluntary muscle activity and assistive torque provided to the knee joint ${ }^{10}$. During knee extension training with the knee HAL-SJ, the patient was seated at the end of a bed. In contrast, for knee flexion treatment, the patient was asked to lay prone on a bed. The patient performed 5 sets of knee HAL-SJ-assisted knee-extension in one session and flexion exercises at a frequency of 10 exercises/set ${ }^{5,6)}$. The duration of one training session was about 50 minutes, including fitting and evaluation (Fig. 4A, B and Supplementary video).

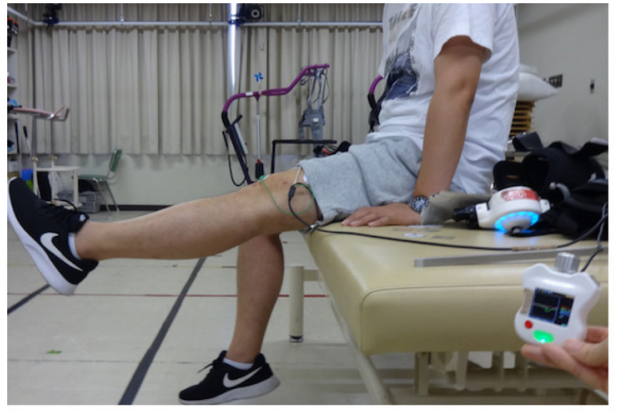

A

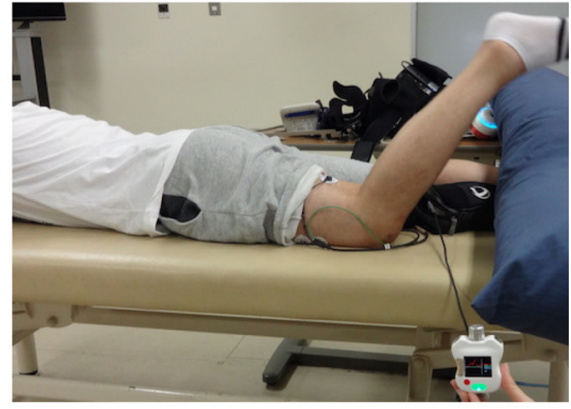

B

Fig. 2. Detection of the bioelectric potential and training simulation prior to beginning the knee HAL-SJ.

A: One day prior to beginning the knee extension training using the single joint type hybrid assistive limb for the knee (knee HAL-SJ), we attached electrodes to the quadriceps muscle.

B: Knee flexion training with attached electrodes to the hamstrings.

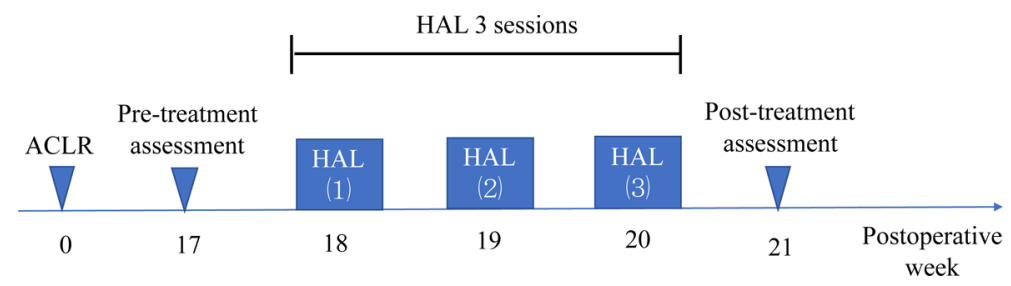

Fig. 3. Postoperative progress and duration of the rehabilitative training using the single joint type hybrid assistive limb for the knee (knee HAL-SJ) following anterior cruciate ligament reconstruction (ACLR).

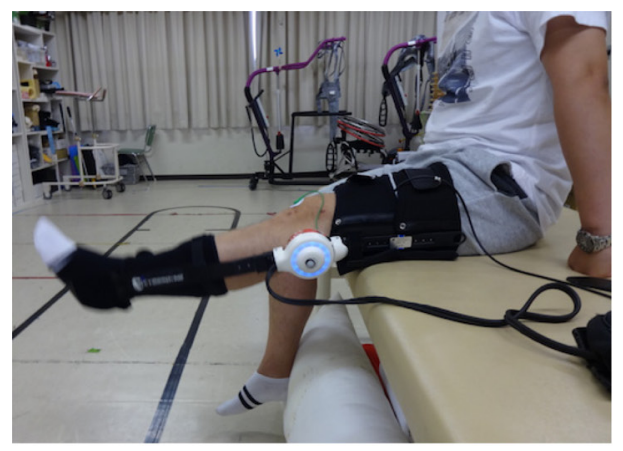

A

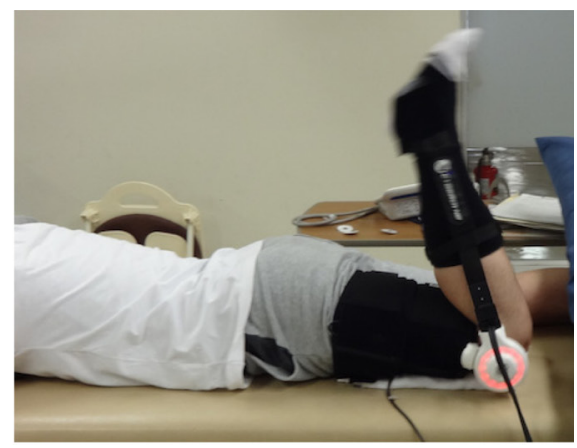

B

Fig. 4. A: Extension training with the single joint type hybrid assistive limb for the knee (knee HAL-SJ) assistance. B: Flexion training with knee HAL-SJ assistance. 
Each training session was carefully observed and evaluated for any adverse events related to the use of the knee HALSJ. Physical evaluations were conducted in postoperative week 17 (pre-HAL) and in postoperative week 21 (post-HAL). Isokinetic evaluation was performed at 60,180 , and $300 \%$ s using an isokinetic dynamometer (Biodex System III; BIODEX Medical Systems, Sakai Inc., Japan), and included strength measurements during knee extension and flexion (measured bilaterally). The limb symmetry index (LSI) was calculated to determine whether a side-to-side difference could be classified as normal or abnormal ${ }^{11)}$. The LSI was defined as the ratio of the injured side to the non-injured side expressed as a percentage (injured/non-injured $\times 100 \%=\mathrm{LSI})$. The active range of motion $(\mathrm{ROM})$, anterior drawer test, pivot shift test, Lachman test, Tegner Activity Scale ${ }^{12}$, Lysholm knee questionnaire ${ }^{12)}$, KT-2000, and International Knee Documentation Committee $(\text { IKDC })^{13)}$ were also measured.

The study was approved by the Institutional Review Board (IRB) of each institution involved in this study and conducted according to the principles of the World Medical Association (WMA) Declaration of Helsinki-Ethical Principles for Medical Research Involving Human Subjects with the amendments made in Seoul, South Korea, in October 2008, with a note of clarification on paragraph 29 added by the WMA General Assembly in Washington (2002) and a note of clarification on paragraph 30 added by the WMA General Assembly in Tokyo (2004). This study was also conducted in accordance with the Japanese Medical Research Involving. Human Subjects Act (WMO) and other guidelines, regulations, and acts. This study was conducted in accordance with approval from the Ethics Committee of the Tsukuba University Faculty of Medicine (approval no.: TCRB18-077).

\section{RESULTS}

Over 3 sessions of treatment, there were no adverse events directly attributed to the HAL-SJ. The LSI peak torque and other outcomes for pre and post-HAL are shown in Table 1. The peak extension torque at all velocities of LSI was higher post-HAL than pre-HAL (Fig. 5). The peak flexion torque at $60^{\circ} / \mathrm{sec}, 300^{\circ} / \mathrm{sec}$ of LSI was higher post-HAL than pre-HAL. The ROM; extension slightly improved from $-2^{\circ}$ pre-HAL to $-1^{\circ}$ post-HAL, and flexion also improved from $124^{\circ}$ pre-HAL to $133^{\circ}$ post-HAL. The Lysholm score increased from 58 pre-HAL to 94 post-HAL interventions.

\section{DISCUSSION}

In the present case, knee HAL-SJ training for a patient who underwent ACLR was safely performed without any observed adverse events, and showed increasing LSI of extension and flexion peak torque even with short-term interventions. Clinical outcomes without peak torque were also improved.

Previous studies indicated that altered biomechanics may increase the risk for second injury, and neuromuscular training should be added to strength training to optimize patient-reported outcome measurements ${ }^{2,14)}$. The influence of quadriceps strength symmetry is an important component of the criteria for rehabilitation progression. The knee HAL-SJ has bioelectric signal balancing capability. This capability is able to adjust balance of detected flexion and extension signals by means of

Table 1. Results of outcomes at Pre and Post-HAL intervention

\begin{tabular}{llcc}
\hline & & Pre-HAL & Post-HAL \\
\hline LSI peak extension torque $(\%)$ at $60 \% \mathrm{~s}$ & 58 & 72 \\
& at $180 \% \mathrm{~s}$ & 62 & 76 \\
& at $300 \% \mathrm{~s}$ & 70 & 88 \\
LSI peak flexion torque $(\%)$ & at $60 \% \mathrm{~s}$ & 77 & 84 \\
& at $180 \% \mathrm{~s}$ & 88 & 71 \\
& at $300 \% \mathrm{~s}$ & 76 & 90 \\
Active range of motion $\left({ }^{\circ}\right)$ & Extension & -2 & -1 \\
& Flexion & 124 & 133 \\
Anterior drawer test & & - & - \\
Pivot shift test & & - & - \\
Lachman test & & - & - \\
Tegner activity scale & & 6 & 6 \\
Lysholm knee questionnaire & & 58 & 94 \\
KT-2000 (mm) & & 2 & 3 \\
IKDC & & A & A \\
\hline
\end{tabular}

HAL: hybrid assistive limb; LSI: limb symmetry index; IKDC: International Knee Documentation Committee; Pre-HAL: before training; Post-HAL: after training.

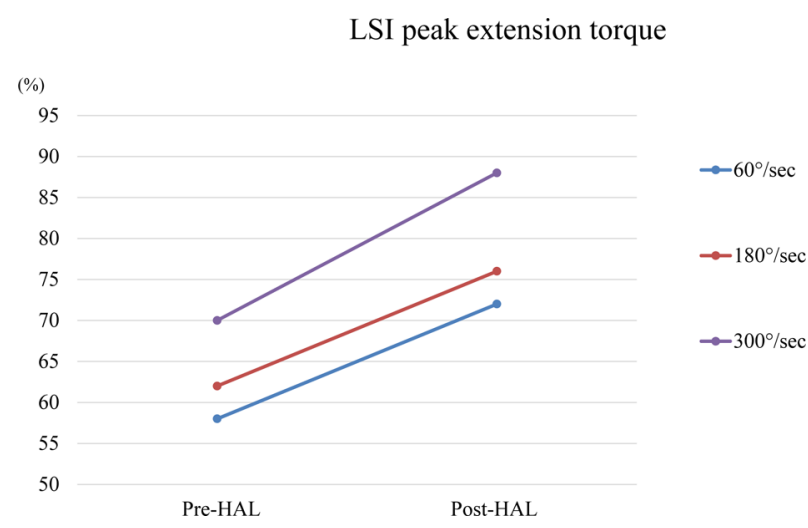

Fig. 5. Results of peak extension torque limb symmetry index (LSI). 
computer processing. Knee HAL-SJ training can provide useful biofeedback to avoid erroneous motor learning ${ }^{15)}$. This study showed that peak torque of LSI, especially extension torque increased. The knee HAL-SJ could help patients be more aware of correct muscle activity and restoration of more optimal knee muscle neuromuscular function.

The findings of this study showed that some of the most commonly used validated clinical scores such as ROM and Lysholm for ACLR were improved. HAL training improved not only knee muscle strength but also knee function. The addition of knee HAL-SJ training to conventional rehabilitation might be more effective in improving muscle activation patterns and facilitate dynamic joint control. Furthermore, improving muscle functions could have a positive influence on motivation and physical activity in patients. These are important data for clinicians who make both rehabilitation and return to sport decisions. Therefore, knee HAL-SJ training could be effective in neuromuscular rehabilitation program for the patient after ACLR.

Despite the efficacy of the knee HAL-SJ training shown in this study, there are several limitations. This is an initial case report and the mechanism for the improvement in muscle function remains unknown. Therefore, further studies with an increased number of patients and a neurophysiological perspective, such as electromyography assessment, are required. Additionally, future studies on the knee HAL-SJ should investigate the acute phase following ACL injury and the long-term effects (1-2-year follow-up) of the knee HA-SJ intervention.

Using the HAL-SJ for ACLR training can be performed safely without adverse events. The present study indicated that knee HAL-SJ training may improve muscle function and reduce dysfunction.

\section{Conflicts of interest}

The authors declare that they have no conflicts of interest.

\section{REFERENCES}

1) van Melick N, van Cingel RE, Brooijmans F, et al.: Evidence-based clinical practice update: practice guidelines for anterior cruciate ligament rehabilitation based on a systematic review and multidisciplinary consensus. Br J Sports Med, 2016, 50: 1506-1515. [Medline] [CrossRef]

2) Hewett TE, Di Stasi SL, Myer GD: Current concepts for injury prevention in athletes after anterior cruciate ligament reconstruction. Am J Sports Med, 2013, 41: 216-224. [Medline] [CrossRef]

3) Sonnery-Cottet B, Saithna A, Quelard B, et al.: Arthrogenic muscle inhibition after ACL reconstruction: a scoping review of the efficacy of interventions. Br J Sports Med, 2019, 53: 289-298. [Medline] [CrossRef]

4) Tashiro T, Kurosawa H, Kawakami A, et al.: Influence of medial hamstring tendon harvest on knee flexor strength after anterior cruciate ligament reconstruction. A detailed evaluation with comparison of single- and double-tendon harvest. Am J Sports Med, 2003, 31: 522-529. [Medline] [CrossRef]

5) Yoshioka T, Kubota S, Sugaya H, et al.: Robotic device-assisted knee extension training during the early postoperative period after opening wedge high tibial osteotomy: a case report. J Med Case Reports, 2017, 11: 213. [Medline] [CrossRef]

6) Yoshioka $\mathrm{T}$, Sugaya H, Kubota S, et al.: Knee-extension training with a single-joint hybrid assistive limb during the early postoperative period after total knee arthroplasty in a patient with osteoarthritis. Case Rep Orthop, 2016, 2016: 9610745. [Medline]

7) Ahn JH, Yoo JC, Yang HS, et al.: Second-look arthroscopic findings of 208 patients after ACL reconstruction. Knee Surg Sports Traumatol Arthrosc, 2007, 15: 242-248. [Medline] [CrossRef]

8) Aglietti P, Giron F, Losco M, et al.: Comparison between single-and double-bundle anterior cruciate ligament reconstruction: a prospective, randomized, single-blinded clinical trial. Am J Sports Med, 2010, 38: 25-34. [Medline] [CrossRef]

9) Goradia VK, Rochat MC, Kida M, et al.: Natural history of a hamstring tendon autograft used for anterior cruciate ligament reconstruction in a sheep model. Am J Sports Med, 2000, 28: 40-46. [Medline] [CrossRef]

10) Aach M, Cruciger O, Sczesny-Kaiser M, et al.: Voluntary driven exoskeleton as a new tool for rehabilitation in chronic spinal cord injury: a pilot study. Spine J, 2014, 14: 2847-2853. [Medline] [CrossRef]

11) Thomeé R, Neeter C, Gustavsson A, et al.: Variability in leg muscle power and hop performance after anterior cruciate ligament reconstruction. Knee Surg Sports Traumatol Arthrosc, 2012, 20: 1143-1151. [Medline] [CrossRef]

12) Tegner Y, Lysholm J: Rating systems in the evaluation of knee ligament injuries. Clin Orthop Relat Res, 1985, (198): 43-49. [Medline]

13) Hefti F, Müller W, Jakob RP, et al.: Evaluation of knee ligament injuries with the IKDC form. Knee Surg Sports Traumatol Arthrosc, 1993, 1: 226-234. [Medline] [CrossRef]

14) Gokeler A, Bisschop M, Benjaminse A, et al.: Quadriceps function following ACL reconstruction and rehabilitation: implications for optimisation of current practices. Knee Surg Sports Traumatol Arthrosc, 2014, 22: 1163-1174. [Medline] [CrossRef]

15) Kubota S, Abe T, Koda M, et al.: Application of a newly developed upper limb single-joint hybrid assistive limb for postoperative C5 paralysis: an initial case report indicating its safety and feasibility. J Clin Neurosci, 2018, 50: 268-271. [Medline] [CrossRef] 